\title{
Prevention of hypernatraemic dehydration in breastfed newborn infants by daily weighing
}

\author{
Konetzny, G ; Bucher, H U ; Arlettaz, R
}

\begin{abstract}
Hypernatraemic dehydration, which predominantly appears in breastfed neonates, can cause serious complications, such as convulsions, permanent brain damage and death, if recognised late. Weight loss $>$ or $=10 \%$ of birth weight could be an early indicator for this condition. In this prospective cohort study from October 2003 to June 2005 in the postnatal ward of the University Hospital Zurich, Switzerland, all term newborns with birth weight $>$ or $=2,500 \mathrm{~g}$ were weighed daily until discharge. When the weight loss was $>$ or $=10 \%$ of birth weight, serum sodium was measured from a heel prick. Infants with moderate hypernatraemia (serum sodium $=146-149 \mathrm{mmol} / \mathrm{l}$ ) were fed supplementary formula milk or maltodextrose $10 \%$. Infants with severe hypernatraemia (serum sodium $>$ or $=150 \mathrm{mmol} / \mathrm{l}$ ) were admitted to the neonatal unit and treated in the same way, with or without intravenous fluids, depending on the severity of the clinical signs of dehydration. A total of 2,788 breastfed healthy term newborns were enrolled. Sixty-seven $(2.4 \%)$ newborns had a weight loss $>$ or $=10 \%$ of birth weight; $24(36 \%)$ of these had moderate and $18(27 \%)$ severe hypernatraemia. Infants born by caesarean section had a 3.4 times higher risk for hypernatraemia than those born vaginally. All newborns regained weight $24 \mathrm{~h}$ after additional fluids. Conclusion: In our study, one out of 66 healthy exclusively breastfed term neonates developed hypernatraemic dehydration. Daily weight monitoring and supplemental fluids in the presence of weight loss $>$ or $=10 \%$ of birth weight allows early detection and intervention, thereby preventing the severe sequellae of hypernatraemic dehydration.
\end{abstract}

DOI: https://doi.org/10.1007/s00431-008-0841-8

Posted at the Zurich Open Repository and Archive, University of Zurich

ZORA URL: https://doi.org/10.5167/uzh-18753

Journal Article

Published Version

Originally published at:

Konetzny, G; Bucher, H U; Arlettaz, R (2009). Prevention of hypernatraemic dehydration in breastfed newborn infants by daily weighing. European Journal of Pediatrics, 168(7):815-818.

DOI: https://doi.org/10.1007/s00431-008-0841-8 


\title{
Prevention of hypernatraemic dehydration in breastfed newborn infants by daily weighing
}

\author{
Gabriel Konetzny • Hans Ulrich Bucher • \\ Romaine Arlettaz
}

Received: 21 May 2008 / Accepted: 10 September 2008 / Published online: 26 September 2008

(C) Springer-Verlag 2008

\begin{abstract}
Hypernatraemic dehydration, which predominantly appears in breastfed neonates, can cause serious complications, such as convulsions, permanent brain damage and death, if recognised late. Weight loss $\geq 10 \%$ of birth weight could be an early indicator for this condition. In this prospective cohort study from October 2003 to June 2005 in the postnatal ward of the University Hospital Zurich, Switzerland, all term newborns with birth weight $\geq 2,500 \mathrm{~g}$ were weighed daily until discharge. When the weight loss was $\geq 10 \%$ of birth weight, serum sodium was measured from a heel prick. Infants with moderate hypernatraemia (serum sodium $=146-149 \mathrm{mmol} / \mathrm{l}$ ) were fed supplementary formula milk or maltodextrose $10 \%$. Infants with severe hypernatraemia (serum sodium $\geq 150 \mathrm{mmol} / \mathrm{l}$ ) were admitted to the neonatal unit and treated in the same way, with or without intravenous fluids, depending on the severity of the clinical signs of dehydration. A total of 2,788 breastfed healthy term newborns were enrolled. Sixty-seven (2.4\%) newborns had a weight loss $\geq 10 \%$ of birth weight; 24 (36\%) of these had moderate and $18(27 \%)$ severe hypernatraemia. Infants born by caesarean section had a 3.4 times higher risk for hypernatraemia than those born vaginally. All newborns regained weight $24 \mathrm{~h}$ after additional fluids. Conclusion: In our study, one out of 66 healthy exclusively breastfed term neonates developed hypernatraemic dehydration. Daily weight monitoring and supplemental fluids in the presence of weight loss $\geq 10 \%$ of birth weight allows early detection and intervention, thereby preventing the severe sequellae of hypernatraemic dehydration.
\end{abstract}

G. Konetzny $(\bowtie) \cdot H$. U. Bucher $\cdot$ R. Arlettaz

Clinic of Neonatology, University Hospital Zurich,

Frauenklinikstrasse 10,

8091 Zurich, Switzerland

e-mail: g.konetzny@bluewin.ch
Keywords Newborns · Breastfeeding · Dehydration . Hypernatraemia

\section{Introduction}

The incidence of severe hypertonic dehydration in exclusively breastfed newborn infants due to the insufficient administration of fluids is increasing [3, 10, 19, 23]. Dehydration is usually defined as a weight loss of more than $10 \%$ of the birth weight $[2,10,16]$. The data currently available are very variable with respect to the incidence reported $[3,8,10,15,16,18,20]$. The studies cannot be compared with one another due to large differences in study designs and the populations examined, and due to the differing practices of various countries concerning medical care of the newborn.

The present study is a prospective collection of data to assess the incidence of hypertonic dehydration in the first week of life of term-born healthy infants, who were exclusively breastfed according to the principles of the "Baby Friendly Hospital Initiative" [26].

\section{Methods}

At the University Hospital of Zurich, Switzerland, between October 2003 and June 2005, we prospectively recorded the daily weights of healthy, exclusively breastfed term newborn infants with a birth weight $\geq 2,500 \mathrm{~g}$. The exclusive use of breast feeding according to the principles of the "Baby-Friendly Hospital Initiative" is routinely carried out in this hospital. Daily weighing until the onset of proven weight gain (considered as weight gain on two consecutive days) is also part of the standard procedure. 
Table 1 Number of dehydrated infants and values of serum sodium

\begin{tabular}{lll}
\hline Sodium values of the newborns with dehydration $(n=67)$ & Number of infants with dehydration & Mean weight loss in \% (range) \\
\hline Sodium $135-145 \mathrm{mmol} / 1$ & $25(37 \%)$ & $10.7(10.0-14.1)$ \\
Sodium $146-149 \mathrm{mmol} / 1$ & $24(36 \%)$ & $10.8(10.0-18.9)$ \\
Sodium $\geq 150 \mathrm{mmol} / 1$ & $18(27 \%)$ & $10.8(10.0-12.2)$ \\
\hline
\end{tabular}

The mean duration of hospitalisation at the maternity ward is 5.5 days for term infants born by vaginal delivery and 7.3 days for those born by caesarean section (data for the year 2004). This makes it possible to monitor almost all newborn infants in the vulnerable time zone between the 3rd and 5th days of life [1, 14, 16, 27]. Sick newborn infants (with respiratory distress syndrome, hypoglycaemia etc.) were excluded from the study, as they all received supplementary formula milk in addition to breast milk (11\% in 2004).

The newborn infants were weighed every morning before the first feed, and usually with the same baby balance, in order to minimise technically related errors as much as possible [24]. For the definition of dehydration, the usual limit of $\geq 10 \%$ loss of birth weight was set, as has been described in the literature [10, 16]. All infants who exceeded this limit were examined for clinical signs of dehydration and other complications, and serum sodium was measured using a capillary blood sample.

Enteral rehydration with breast milk and additional fluids (either formula milk or maltodextrose 10\%) was provided at regular intervals of 3 to $4 \mathrm{~h}$ if the sodium values were below $150 \mathrm{mmol} / \mathrm{l}$. If severe hypertonic dehydration occurred with sodium values $\geq 150 \mathrm{mmol} / \mathrm{l}$, the newborn infants were admitted to the neonatal intermediate care unit and, according to their clinical condition, were either rehydrated orally as described above or with additional intravenous fluids $(50-100 \mathrm{ml} / \mathrm{kg} / \mathrm{d})$. Serum sodium was checked after $8-12 \mathrm{~h}$. At the same time, the mothers were given advice on breast feeding (i.e. positioning the infant, milk expression) by trained lactation consultants. All

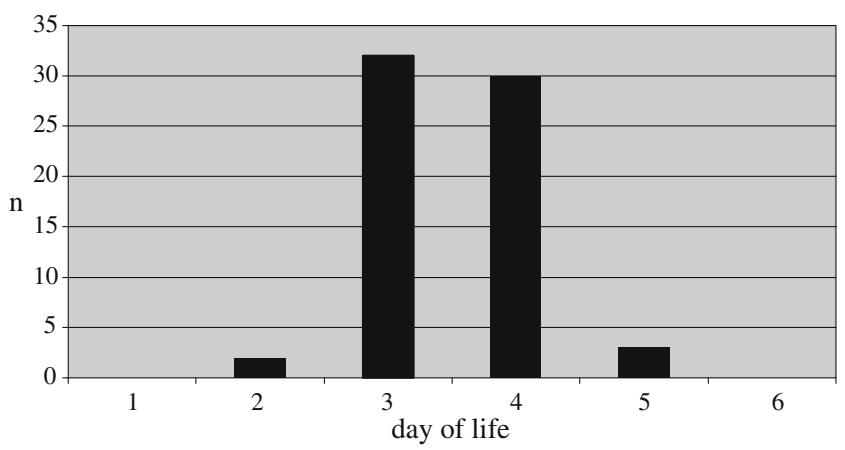

Fig. 1 Day of life and corresponding number of infants reaching or exceeding the $10 \%$ threshold of weight loss from birth weight infants received a repeat clinical examination, at the latest before discharge.

\section{Results}

During the period from October 2003 to June 2005, a total of 2,788 healthy infants born at term with birth weight $\geq 2,500 \mathrm{~g}$ and who had been exclusively breastfed were included in the study. Sixty-seven $(2.4 \%)$ infants had a loss of weight $\geq 10 \%$ of their birth weight. In 24 infants, this was associated with a moderate and in 18 infants with a severe hypernatraemia $(0.6 \%$ of the total population).

Table 1 shows the distribution of sodium values and weight loss in the dehydrated infants $(n=67)$.

Figure 1 shows the day of life at which the $10 \%$ threshold of weight loss from birth weight was reached or exceeded.

Infants born by caesarean section had a significantly higher incidence of dehydration (odds ratio $[\mathrm{OR}]=3.4 ; 95 \%$ confidence interval [CI] 2.1-5.7), as can be seen in Table 2.

An incidental observation in our study was that many more infants in the pilot phase, i.e. in the first 6 months of data collection, suffered from dehydration than in the intervention phase, i.e. in the following 15 months $(5.4 \%$ compared with $1.3 \%, p<0.01$ ).

\section{Discussion}

In this study, the incidence of dehydration (defined as weight loss $\geq 10 \%$ of birth weight) of exclusively breastfed term infants with a birth weight $\geq 2,500 \mathrm{~g}$ was $2.4 \%$. Our explanation for the difference in the incidence of dehydration in the pilot phase and in the intervention phase as

Table 2 Total study population and newborn infants with dehydration classified according to the method of delivery

\begin{tabular}{lllrlr}
\hline & $n$ & Dehydration & \multicolumn{2}{l}{$\begin{array}{l}\text { Hypernatraemic } \\
\text { dehydration }\end{array}$} \\
\hline Vaginal birth & 1,960 & 28 & $1.4 \%$ & 18 & $0.9 \%$ \\
Caesarean section & 828 & 39 & $4.7 \%$ & 24 & $2.9 \%$ \\
OR (95\% CI) & & $3.4(2.1-5.7)$ & $3.2(1.8-6.2)$ \\
\hline
\end{tabular}


described above is the use of more stringent controls and the institution of fluid supplementation, even for those infants who were near the " $10 \%$ threshold," if breastfeeding problems were also present. This illustrates the importance of successful awareness training of the medical and nursing staff regarding this issue, with more consistent and timely intervention, even by applying the principles of the "BabyFriendly Hospital Initiative."

For infants with moderate hypertonic dehydration defined as sodium values between 146 und $149 \mathrm{mmol} / \mathrm{l}$, the incidence was $0.9 \%$, whereas this level of hypernatraemia might be physiological [14]. For those with severe hypertonic dehydration defined as sodium values $\geq 150 \mathrm{mmol} / \mathrm{l}$, the incidence was $0.6 \%$. In the literature, the incidence for hypertonic dehydration varies widely $[9$, $16,18]$. However, it is difficult to make comparisons due to differences in the organisation of medical care (such as the time of discharge, organisation of out-patient follow-up) in the individual countries, differences in the populations studied and varying study inclusion criteria. We did not find a correlation between the serum sodium level and the degree of weight loss, as described in the literature [18]. This may possibly be explained by the low number of dehydrated newborn infants.

The nadir of the natural course of weight loss, or the time at which the $10 \%$ threshold was reached or exceeded in exclusively breastfed infants, occurred at days 3 and 4 and is in agreement with the majority of studies in which newborn infants were regularly weighed during the first few days of life [14, 16, 27]. If weight controls are missing or are only performed sporadically, there is a danger of making the diagnosis too late, with the necessity for rehospitalisation and the risk of neurological, vascular and other complications $[6,23,25]$. In our study population, babies with severe hypertonic dehydration showed only a few, non-specific clinical features, such as hypotension and increased fatigue. None of the infants showed vascular or neurological signs at the time of discharge. A weakness of this descriptive study was the lack of a control group and that we observed the development of hypernatraemia only within the first few days of life, whilst the infants were still in the maternity unit.

With respect to the $10 \%$ threshold, a study from Holland has shown that a more precise assessment of the risk of dehydration may be possible with the aid of a chart for relative weight change, particularly in the first week of life [27]. The 10\% threshold, however, remains the simplest and fastest possibility for detecting infants at risk, particularly in the setting of out-patient care following a short hospitalisation period $[5,14,22]$.

Birth by caesarean section was identified as a risk factor for dehydration, with an OR of 3.4 (95\% CI 2.1-5.7). The factors that are responsible for this phenomenon probably lie in the delayed start of lactation and in poorer drinking patterns at the breast following caesarean section $[4,16]$.

\section{Conclusion}

In summary, daily weighing during the first 4-5 days of life is a simple and cost-effective method for recording an imminent or existing dehydration in exclusively breastfed newborn infants. It allows the possibility of timely rehydration and the early recognition of breastfeeding problems, especially following delivery by caesarean section $[1,7,11-13,17-19,21]$.

\section{References}

1. American Academy of Pediatrics Policy Statement (2005) Breastfeeding and the use of human milk. Pediatrics 115:496506. doi:10.1542/peds.2004-2491

2. Cohn A (2005) A simple method for assessing if weight loss is greater or less than 10\%. Arch Dis Child 90:88. doi:10.1136/ adc. 2004.061507

3. Cooper WO, Atherton HD, Kahana M, Kotagal UR (1995) Increased incidence of severe breastfeeding malnutrition and hypernatremia in a metropolitan area. Pediatrics 96:957-960

4. Dewey KG, Nommsen-Rivers LA, Heinig MJ, Cohen RJ (2003) Risk factors for suboptimal infant breastfeeding behavior, delayed onset of lactation, and excess neonatal weight loss. Pediatrics 112:607-619. doi:10.1542/peds.112.3.607

5. Edmonson MB, Stoddard JJ, Owens LM (1997) Hospital readmission with feeding-related problems after early postpartum discharge of normal newborns. JAMA 278:299-303. doi:10.1001/ jama.278.4.299

6. Escobar GJ, Gonzales VM, Armstrong MA, Folck BF, Xiong B, Newman TB (2002) Rehospitalization for neonatal dehydration: a nested case-control study. Arch Pediatr Adolesc Med 156:155-161

7. Harding D, Cairns P, Gupta S, Cowan F (2001) Hypernatraemia: why bother weighing breast fed babies? Arch Dis Child Fetal Neonatal Ed 85:F145. doi:10.1136/fn.85.2.F145a

8. Harding D, Moxham J, Cairns P (2003) Weighing alone will not prevent hypernatraemic dehydration. Arch Dis Child Fetal Neonatal Ed 88:F349. doi:10.1136/fn.88.4.F349

9. Iyer NP, Srinivasan R, Evans K, Ward L, Cheung WY, Matthes JWA (2008) Impact of an early weighing policy on neonatal hypernatraemic dehydration and breast feeding. Arch Dis Child 93:297-299. doi:10.1136/adc.2006.108415

10. Laing IA, Wong CM (2002) Hypernatraemia in the first few days: is the incidence rising? Arch Dis Child Fetal Neonatal Ed 87: F158-F162. doi:10.1136/fn.87.3.F158

11. Livingstone VH, Willis CE, Abdel-Wareth LO, Thiessen P, Lockitch G (2000) Neonatal hypernatremic dehydration associated with breastfeeding malnutrition: a retrospective survey. CMAJ 162:647-652

12. Macdonald PD (2007) Postnatal weight monitoring should be routine. Arch Dis Child 92:374-375

13. Macdonald PD, Grant L, Ross SR (2003) Hypernatraemia in the first few days: a tragic case. Arch Dis Child Fetal Neonatal Ed 88: F350. doi:10.1136/fn.88.4.F350

14. Macdonald PD, Ross SR, Grant L, Young D (2003) Neonatal weight loss in breast and formula fed infants. Arch Dis Child Fetal Neonatal Ed 88:F472-F476. doi:10.1136/fn.88.6.F472 
15. Maisels MJ, Gifford K (1983) Breast-feeding, weight loss, and jaundice. J Pediatr 102:117-118. doi:10.1016/S0022-3476(83) 80305-9

16. Manganaro R, Mamì C, Marrone T, Marseglia L, Gemelli M (2001) Incidence of dehydration and hypernatremia in exclusively breast-fed infants. J Pediatr 139:673-675. doi:10.1067/mpd.2001.118880

17. McKie A, Young D, Macdonald PD (2006) Does monitoring newborn weight discourage breast feeding? Arch Dis Child 91:44-46. doi:10.1136/adc.2005.074484

18. Moritz ML, Manole MD, Bogen DL, Ayus JC (2005) Breastfeeding-associated hypernatremia: are we missing the diagnosis? Pediatrics 116:e343-e347. doi:10.1542/peds.2004-2647

19. Neifert MR (2001) Prevention of breastfeeding tragedies. Pediatr Clin North Am 48:273-297

20. Oddie S, Richmond S, Coulthard M (2001) Hypernatraemic dehydration and breast feeding: a population study. Arch Dis Child 85:318-320. doi:10.1136/adc.85.4.318

21. Odeka EB (2003) Weighing of breast fed babies is important. Arch Dis Child Fetal Neonatal Ed 87:F158-F162, e-letter in response to Laing
22. Paul IM, Phillips TA, Widome MD, Hollenbeak CS (2004) Costeffectiveness of postnatal home nursing visits for prevention of hospital care for jaundice and dehydration. Pediatrics 114:10151022. doi:10.1542/peds.2003-0766-L

23. Rosenbloom AL (2004) Permanent brain damage from hypernatremic dehydration in breastfed infants: patient reports. Clin Pediatr (Phila) 43:855-857. doi:10.1177/000992280404300911

24. Savenije OEM, Brand PLP (2006) Accuracy and precision of test weighing to assess milk intake in newborn infants. Arch Dis Child Fetal Neonatal Ed 91:F330-F332. doi:10.1136/adc.2005.091876

25. Shroff R, Hignett R, Pierce C, Marks S, van't Hoff W (2006) Lifethreatening hypernatraemic dehydration in breastfed babies. Arch Dis Child 91:1025-1026. doi:10.1136/adc.2006.095497

26. UNICEF (1991) The Baby-Friendly Hospital Initiative. Ten steps to successful breastfeeding. Available online at: http://www. unicef.org/programme/breastfeeding/baby.htm

27. van Dommelen $P$, van Wouwe JP, Breuning-Boers JM, van Buuren S, Verkerk PH (2007) Reference chart for relative weight change to detect hypernatraemic dehydration. Arch Dis Child 92:490-494. doi:10.1136/adc.2006.104331 